\title{
Is routine measurement of TSH in hospitalized patients necessary?
}

\author{
Amir Bashkin ${ }^{1,2}$, Eliran Yaakobi ${ }^{2}$, Marina Nodelman ${ }^{1,2}$ and Ohad Ronen $^{2,3}$ \\ 'Department of Endocrinology, Galilee Medical Center, Nahariya, Israel \\ ${ }^{2}$ Azrieli Faculty of Medicine, Bar-Ilan University, Safed, Israel \\ ${ }^{3}$ Department of Otolaryngology Head and Neck Surgery, Galilee Medical Center, Nahariya, Israel \\ Correspondence should be addressed to A Bashkin: amirb@gmc.gov.il
}

\begin{abstract}
TSH routine testing in hospitalized patients has low efficacy, but may be beneficial in a selected subgroup of patients. Our aim was to evaluate the efficacy of routine thyroid function tests among patients admitted to internal medicine departments. It is a retrospective study. A randomly selected cohort of hospitalized patients with abnormal thyroid-stimulating hormone (TSH) blood tests drawn as part of admission protocol. Patient data were collected from the electronic medical files and analyzed for its efficacy. TSH as a screening test was proven unnecessary in $75 \%$ (174) of the study population. Leading causes were non-thyroidal illness syndrome, drugs affecting the test results and subclinical disorders. TSH testing was found to be clinically helpful in only 9 patients; however, all of them had other clinical need for TSH testing. We found a clinically abnormal TSH in 20 patients, hypothyroidism in 11 patients and thyrotoxicosis in 9 patients. Low efficacy ascribed to TSH screening test by this study correlates with recent recommendations that indicate TSH screening in admitted patients only with accompanying clinical suspicion. Most probably, the majority of patients found by screening to have thyrotoxicosis have non-thyroidal illness or drug effects so the threshold for FT4 to diagnose overt thyrotoxicosis should be higher than that in ambulatory patients. In elderly patients, clinically relevant TSH disturbances are more frequent and are harder to diagnose, therefore, TSH screening in this group of patients might be beneficial.
\end{abstract}

\author{
Key Words \\ - TSH \\ - hypothyroidism \\ - non-thyroidal illness \\ syndrome
}

\section{Introduction}

Routine TSH blood level screening test for thyroid function in hospitalized patients with other acute disease is not recommended by the leading associations of thyroid medicine $(1,2,3,4)$. Thyroid dysfunction during hospitalization is usually the result of stress due to the acute illness that led to hospitalization or the effect of drug therapy. In rare cases, thyroid dysfunction may result from thyroid disease and without treatment may adversely affect hospitalization. However, the studies that examined the usefulness of routine TSH measurements during hospitalization were performed several decades

http://www.endocrineconnections.org https://doi.org/10.1530/EC-18-0004

O2018 The authors Published by Bioscientifica Ltd ago and since then the TSH test has become more accurate and less expensive. In addition, the population is aging and in most cases, signs and symptoms alone do not signal thyroid dysfunction, except in serious disorders. In our medical center protocol, all patients admitted to the internal medicine departments are routinely screened for TSH levels. The purpose of this study was to find the frequencies of inpatient thyroid dysfunctions and examine whether the routine measurement of TSH is beneficial, unnecessary or even harmful for patients hospitalized in internal medicine departments. 


\section{Materials and methods}

The study was approved by the institutional review board (registration number: NHR009914) that granted exemption from informed consent due to the retrospective design of the study. The study is a retrospective study of data of patients from the six internal medicine departments who were hospitalized for any reason. Data were collected from the Medical Center's electronic medical records. TSH tests of patients hospitalized during November 2014 to February 2016 were randomly chosen and reviewed. The patients were selected consecutively, from 86 random admission days. For patients who were hospitalized twice during that period, only the first hospitalization was included. Only abnormal TSH results were included in the study group. The Medical Center's protocol states that all patients with a lower than normal TSH level be routinely tested for FT4 and FT3, and all patients who had a higher than normal TSH level be routinely tested for FT4. We collected data that included preadmission impaired laboratory thyroid function results and preadmission diagnosis of thyroid disease. We also collected data on the treatment during hospitalization, including blood tests, imaging tests, endocrinologist counseling, medication and recommendations in the discharge letter. We also examined whether the patient was treated with a drug that would significantly affect thyroid function from a predetermined list. There are many drugs that may affect thyroid function and only the most potent drugs have been tested, including glucocorticoids, levothyroxine, Mercaptizol, Propylthiouracil, Amiodarone, opioids and drugs that enhance T4 metabolism through the enhancement of cytochrome P450 3A4 such as phenytoin and carbamazepine $(5,6)$.

Patients were divided into the following diagnoses: overt hypothyroidism, subclinical hypothyroidism, overt thyrotoxicosis, subclinical thyrotoxicosis and nonthyroidal illness syndrome (NTIS) and/or effect of drugs. It is impossible to differentiate between the latter two based on thyroid function test $(7,8)$. NTIS or thyrotoxicosis was diagnosed according to the FT4 and FT3 levels. If TSH was low and one of the hormones was high, thyrotoxicosis was diagnosed, otherwise NTIS was diagnosed. FT3 level above the middle of the norm was considered high and FT4 slightly above the middle of the normal range $(1.3 \mathrm{ng} / \mathrm{dL})$ was considered high due to suppression of the transition from FT4 to FT3 in stress.

A senior endocrinologist (A.B.) reviewed all cases and determined whether the work-up and recommendations were justified. In addition, it was determined whether

$$
\text { http://www.endocrineconnections.org }
$$

the TSH survey performed on the admission profile was certainly beneficial, probably beneficial, unnecessary or probably harmful.

\section{Statistical methods}

Quantitative data were described using averages and s.D., median and range. Qualitative data were described using frequency and percentage. A correlation between age and the different categories of TSH test efficacy was done using analysis of variance with a $P$ value under 0.05 considered statistically significant. Sample size was determined according to the prevalence of abnormal TSH for the year 2015 (in patients hospitalized in internal medicine departments).

TSH, FT4 and FT3 levels were measured using chemiluminescent microparticle immunoassay in the Architect i2000SR (Abbott Diagnostics), in which the normal ranges for TSH were $0.35-4.98 \mathrm{IU} / \mathrm{mL}$, for FT4 $0.7-1.48 \mathrm{ng} / \mathrm{dL}$ and for FT3 $1.71-3.71 \mathrm{pg} / \mathrm{mL}$.

\section{Results}

The study group consisted of 232 patients with an abnormal TSH level on admission to internal medicine departments. In 2015, there were 20,163 TSH tests done, almost all on admission. Of them, 1785 measurements were below the normal range and 664 were above it; together, they represent $11.8 \%$ abnormal TSH results. The 232 randomly selected patients therefore represent about 1966 TSH screening tests. Out of the 232 patients, 178 (77\%) had abnormally low TSH levels, and 54 (23\%) had abnormally high TSH levels. Patients' characteristics as well as preadmission thyroid function diagnosis and pharmacologic influence distribution can be seen in Table 1.

Most patients in the study group with abnormal TSH (201, 87\%) did not undergo any further work-up during their hospitalization and in the vast majority (98.7\%) of them, this was found to be justified. The remaining patients (31, 13\%) underwent work-up during hospitalization, yet, for the most part (61\%), the work-up was found to be unnecessary by our team's endocrinologist.

\section{Thyroid dysfunction diagnosis during hospitalization}

NTIS or the effect of drugs was the most common diagnosis in patients with abnormal TSH result (the study group) as it was seen in 121 (52.1\%). The other diagnoses

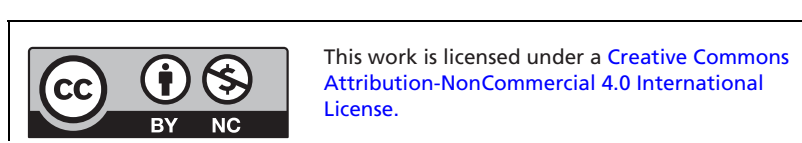


Table 1 Patients' characteristics.

\begin{tabular}{|c|c|}
\hline Parameter & $\boldsymbol{N}(\%)$ \\
\hline \multicolumn{2}{|l|}{ Age } \\
\hline Average \pm s.D., median, range & $\begin{array}{c}65.5 \pm 17.5,70 \\
19-96 \text { years }\end{array}$ \\
\hline \multicolumn{2}{|l|}{ Gender } \\
\hline Female & $119(51)$ \\
\hline \multicolumn{2}{|l|}{ Thyroid function on admission } \\
\hline None & $161(69)$ \\
\hline Treated hypothyroidism & $33(14)$ \\
\hline Untreated hypothyroidism & $16(7)$ \\
\hline Other (including hyperthyroidism) & $22(10)$ \\
\hline No known disturbance & $161(69)$ \\
\hline \multicolumn{2}{|l|}{ Pharmacologic influence } \\
\hline None & $80(35)$ \\
\hline Glucocorticosteroids & $103(44)$ \\
\hline Opiates & $6(3)$ \\
\hline Antiepileptic & $2(1)$ \\
\hline Amiodarone & $16(7)$ \\
\hline L-thyroxin & $34(15)$ \\
\hline Other & $5(2)$ \\
\hline
\end{tabular}

S.D. - standard deviation.

were subclinical thyrotoxicosis in 48 (20.7\%), subclinical hypothyroidism in 43 (18.5\%), overt hypothyroidism in $11(4.7 \%)$ and overt thyrotoxicosis in nine patients (3.9\%) (Fig. 1).

\section{Final analysis and evaluation of efficiency}

After each case was evaluated by a senior endocrinologist, the following were found (Tables 2 and 3): Of the 232 patients with an abnormal TSH result, in 174 (75\%), the test was determined as unnecessary mainly due to NTIS diagnosis or the effects of drugs and subclinical disorders. In 37 (16\%) patients, the TSH test was found unnecessary and also led to unnecessary investigations; included in this group are 25 patients with NTIS and 12 with subclinical disorders. In 12 patients, it was impossible to determine whether the test was indeed necessary but did not require treatment or work-up during hospitalization. In only nine patients was it possible to state clearly that the test was helpful because it led to treatment change in a justified manner. A trend toward statistically significant correlation was found only between the various efficacy categories and age (ANOVA, $P=0.062$ ).

\section{Discussion}

The study found that TSH as a screening test in hospitalized patients identified a very low rate of thyroid dysfunction requiring a change in work-up at hospitalization and a high rate of clinically insignificant disorders, similar to that found in other studies $(9,10,11,12)$. In the study group (232 patients with an abnormal TSH level), most of the disorders in the cohort (52.1\%) were probably due to NTIS or to drug effects (NTIS/drugs). Overt thyrotoxicosis was found in $3.9 \%$ of patients with abnormal TSH and overt hypothyroidism in $4.7 \%$, meaning that approximately 1966 patients had TSH levels measured in

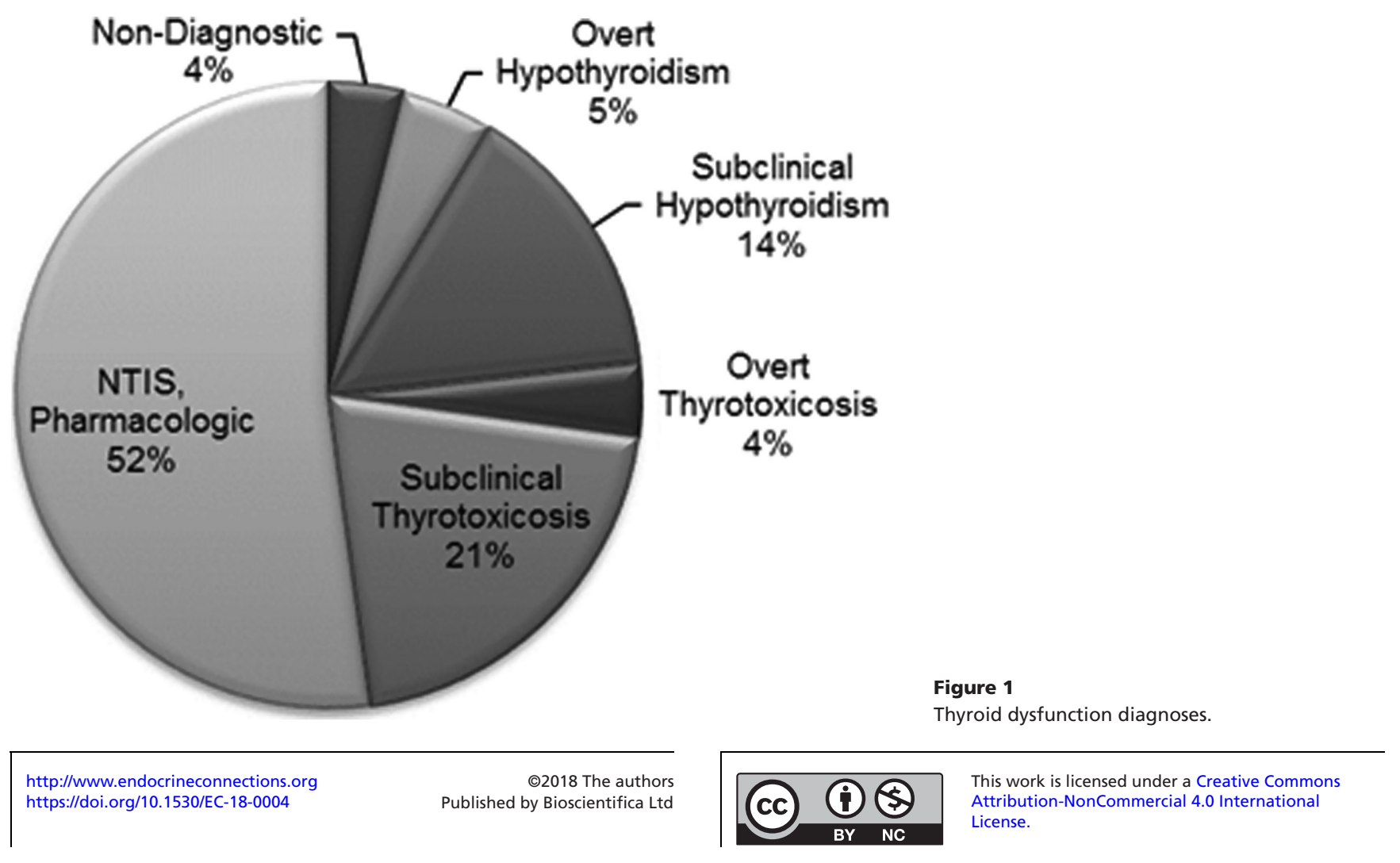


Table 2 Recommendations for further work-up in a community healthcare facility.

\begin{tabular}{lcc}
\hline Recommendation & Number of patients (\%) \\
\cline { 1 - 2 } & $173(75)$ \\
TSH level & $18(8)$ \\
TSH level+ endocrinologist consult & $31(13)$ \\
Other recommendation & $10(4)$ \\
Total & $232(100)$
\end{tabular}

Most patients were discharged with no further recommendations in a community healthcare facility.

order to find overt thyrotoxicosis in about $0.5 \%$ and overt hypothyroidism in about $0.6 \%$. Of the patients who were found to have clinical disorders, in some the disorder was known and in others superfluous for the hospitalization. Of the 11 patients with clinical hypothyroidism, at least $55 \%$ had prior hypothyroidism. Of the nine patients with clinical thyrotoxicosis, in eight patients FT3 was not at all high but in the lower half of the normal range, and only FT4 was slightly increased 1.25 times, so the diagnosis might not be correct, but rather delayed deiodination from T4 to T3 due to NTIS or drugs (13). Of the nine patients with thyrotoxicosis, only three had a complete suppression of TSH (below $0.1 \mathrm{IU} / \mathrm{mL}$ ), which again raises suspicion that the main disorder is NTIS/drugs.

The most common disease in the thyroid gland that causes dysfunction is Hashimoto's disease, which leads to thyroid inactivity 8-10 times more often in women, and its incidence increases with age. Thyrotoxicosis due to thyroid disease is also much more common in women $(14,15,16)$. In our cohort of patients with abnormal TSH, the incidence was equally distributed across genders (51\% women), greatly reinforcing the suspicion that in most cases, the disorder was related to stress and drugs.

The high rate of clinically insignificant disorders led to a high rate of unnecessary work-up, especially in patients without a preadmission thyroid disorder. Contrary to expectations, the prevalence of subclinical thyrotoxicosis was higher than subclinical hypothyroidism and probably

Table 3 TSH test efficacy.

\begin{tabular}{lcc}
\hline Clinically efficacy of TSH test & & Number of patients (\%) \\
\cline { 1 - 1 } Certainly beneficial & $9(3.9)$ \\
Probably beneficial & $12(5.2)$ \\
Unnecessary & $174(75)$ \\
Probable harmful & $37(15.9)$ \\
Total & $232(100)$ \\
\hline
\end{tabular}

Cases were evaluated by a senior endocrinologist to determine the clinical efficacy of the TSH test. Only a trend toward statistically significant correlation was found between the various efficacy categories and age (ANOVA, $P=0.062$ ).

http://www.endocrineconnections.org

https://doi.org/10.1530/EC-18-0004

(C2018 The authors Published by Bioscientifica Ltd related to the effect of stress and drugs. The most common affecting drug was glucocorticoids in $44 \%$ of patients with abnormal TSH. Glucocorticoids are known to cause suppression of TSH and an increase in FT4 due to the inhibition of the transition from T4 to T3, which is probably influenced by the high rate of thyrotoxicosis. Other drugs that suppress TSH, such as dopamine and somatostatin antagonists, have also been used in the hospital.

In our cohort of patients, the TSH test was certainly necessary, and treatment was adjusted accordingly in only nine patients $(3.9 \%)$. All of them had a clear reason to examine their TSH level because they were either on a drug that affects thyroid function such as levothyroxine or Amiodarone or because of a highly suspicious clinical picture of thyroid dysfunction.

Iglesias and colleagues performed the most comprehensive test of the incidence of thyroid dysfunction in hospitalization (9). In the study, TSH and thyroid hormones were measured as a screening test in geriatric departments and their findings were: 3\% overt hypothyroidism, 6\% subclinical hypothyroidism, 3\% overt thyrotoxicosis and $2 \%$ subclinical thyrotoxicosis. In the present study, however, there was approximately 5.5 times lower incidence of clinical disorders in thyroid function, most probably due to the age difference. In our study, the mean age of 232 patients with an abnormal TSH was 65 years with a S.D. of 17.5. In contrast, the group of Iglesias had an average age of 84 years and a S.D. of 6.5 years. Some of the studies that examined the utility of routine TSH measurement were performed over two decades ago $(12,18,19)$ and found that in elderly patients, thyroid dysfunction is common and harder to diagnose clinically; therefore, TSH screening in this group of patients might be beneficial.

\section{Study limitations}

The researchers hypothesized that NTIS is clinically insignificant, in accordance with the paradigm of physiological adaptation to acute disease. Although the ATA guidelines do not recommend treating NTIS, the authors wish to emphasize that the recommendation is based on very little information from RCT studies. There is also evidence of beneficial effects of low-dose T3 and an increase in the expression of D3 that breaks up thyroid hormones, which raises concern about hypothyroidism in tissues (3). In patients treated for hypothyroidism prior to hospitalization and develop NTIS, it is recommended to continue treatment, as cessation of treatment may increase

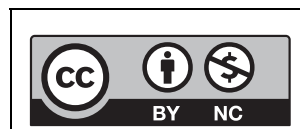

This work is licensed under a Creative Commons Attribution-NonCommercial 4.0 International License. 
the risk of mixedema coma (3). In the ATA guidelines for patients with hypothyroidism prior to hospitalization, it is recommended to adjust the treatment to achieve a normal TSH level, but in contrast to the guidelines we regarded TSH up to $10 \mathrm{IU} / \mathrm{mL}$ as clinically insignificant. This is because in some patients with NTIS, TSH can increase up to $20 \mathrm{IU} / \mathrm{mL}$ during recovery (20). In order to accurately evaluate the incidence of thyroid dysfunction and the usefulness of TSH measurement, it is preferable to perform a prospective study when data about prior thyroid disease and signs and symptoms of thyroid dysfunction are gathered. In addition, it is more accurate to measure FT4 and FT3 in all subjects, and not only in those with an abnormal TSH, in order to identify all patients with NTIS and to differentiate thyrotoxicosis from NTIS.

In patients with partial suppression of TSH (TSH level above $0.1 \mathrm{IU} / \mathrm{L}$ ), it is very unlikely that there is significant thyrotoxicosis. On the other hand, hypothyroidism cannot be diagnosed in most patients if TSH is less than $10 \mathrm{IU} / \mathrm{mL}$ due to the effect of NTIS $(7,8,21)$. Therefore, in patients with mildly increased TSH levels, it is recommended to repeat a TSH blood test after recovery from an acute disease; this recommendation also applies for subclinical thyrotoxicosis with partial suppression of TSH levels above 0.1 IU/L.

\section{Conclusions}

The low efficacy ascribed to TSH screening test by this study correlates with recent recommendations by leading endocrinology associations that indicate TSH screening in admitted internal medicine patients only with accompanied clinical suspicion of clinical hyper/ hypothyroidism or previous thyroidal disturbance. It is possibly cost-effective to screen the elderly population. Avoiding TSH screenings in all admitted patients has a profound cost-effective potential and should be considered as a necessary change to existing admission protocol.

\section{Declaration of interest}

The authors declare that there is no conflict of interest that could be perceived as prejudicing the imparity of the research reported.

\section{Funding}

This research did not receive any specific grant from any funding agency in the public, commercial or not-for-profit sector.

\section{Author contribution statement}

The study was designed and conducted solely by the authors. The manuscript has been seen and approved by all authors. Dr B A and

http://www.endocrineconnections.org https://doi.org/10.1530/EC-18-0004

() 2018 The authors Published by Bioscientifica Ltd
Dr Y E wrote the first draft of the manuscript, and the manuscript was edited by all authors.

\section{Acknowledgements}

The authors wish to thank Orly Yakir for the statistical analysis.

\section{References}

1 Fliers E, Bianco AC, Langouche L \& Boelen A. Thyroid function in critically ill patients. Lancet Diabetes and Endocrinology 20153 816-825. (https://doi.org/10.1016/S2213-8587(15)00225-9)

2 Baskin HJ, Cobin RH, Duick DS, Gharib H, Guttler RB, Kaplan MM \& Segal RL. American Association of Clinical Endocrinologists. American Association of Clinical Endocrinologists medical guidelines for clinical practice for the evaluation and treatment of hyperthyroidism and hypothyroidism. Endocrine Practice 20028 457-469. Erratum in: Endocrine Practice 2008 14 802-803. (https:// doi.org/10.4158/1934-2403-8.6.457)

3 Jonklaas J, Bianco AC, Bauer AJ, Burman KD, Cappola AR, Celi FS, Cooper DS, Kim BW, Peeters RP, Rosenthal MS, et al. American Thyroid Association Task force on thyroid hormone replacement. Guidelines for the treatment of hypothyroidism: prepared by the American Thyroid Association task force on thyroid hormone replacement. Thyroid 201424 1670-1751. (https://doi.org/10.1089/ thy.2014.0028)

4 Garber JR, Cobin RH, Gharib H, Hennessey JV, Klein I, Mechanick JI, Pessah-Pollack R, Singer PA \& Woeber KA. American Association of Clinical Endocrinologists and American Thyroid Association Taskforce on Hypothyroidism in Adults. Clinical Practice Guidelines for Hypothyroidism in Adults: cosponsored by the American Association of Clinical Endocrinologists and the American Thyroid Association. Endocrine Practice 201218 988-1028. (https://doi. org/10.4158/EP12280.GL)

5 Stathatos N. Thyroid physiology. Medical Clinics of North America 201296 165-173. (https://doi.org/10.1016/j.mcna.2012.01.007)

6 Kundra P \& Burman KD. The effect of medications on thyroid function tests. Medical Clinics of North America 201296 283-295. (https://doi.org/10.1016/j.mcna.2012.02.001)

7 De Groot LJ. Non-thyroidal illness syndrome is a manifestation of hypothalamic-pituitary dysfunction, and in view of current evidence, should be treated with appropriate replacement therapies. Critical Care Clinics 200622 57-86, vi. (https://doi.org/10.1016/j. ccc.2005.10.001)

8 Farwell AP. Nonthyroidal illness syndrome. Current Opinion in Endocrinology, Diabetes and Obesity 201320 478-484. (https://doi. org/10.1097/01.med.0000433069.09294.e8)

9 Iglesias P, Muñoz A, Prado F, Guerrero MT, Macías MC, Ridruejo E, Tajada P \& Díez JJ. Alterations in thyroid function tests in aged hospitalized patients: prevalence, aetiology and clinical outcome. Clinical Endocrinology 2009 70 961-967. (https://doi.org/10.1111/ j.1365-2265.2008.03421.x)

10 De Alfieri W, Nisticò F, Borgogni T, Riello F, Cellai F, Mori C, Nante N $\&$ Di Bari M. Thyroid hormones as predictors of short- and long-term mortality in very old hospitalized patients. Journals of Gerontology: Series A, Biological Sciences and Medical Sciences 201368 1122-1128. (https://doi.org/10.1093/gerona/glt012)

11 Mingote E, Meroño T, Rujelman R, Marquez A, Fossati P, Gurfinkiel M, Schnitman M, Brites F, Faingold C \& Brenta G. High TSH and low T4 as prognostic markers in older patients. Hormones $201211350-355$.

12 Small M, Buchanan L \& Evans R. Value of screening thyroid function in acute medical admissions to hospital.

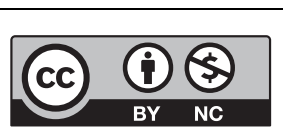

This work is licensed under a Creative Commons Attribution-NonCommercial 4.0 International License. 
Clinical Endocrinology 199032 185-191. (https://doi. org/10.1111/j.1365-2265.1990.tb00854.x)

13 Tognini S, Marchini F, Dardano A, Polini A, Fedeghini M, Castiglioni M \& Monzani F. Non-thyroidal illness syndrome and short-term survival in a hospitalised older population. Age and Ageing 201039 46-50. (https://doi.org/10.1093/ageing/afp197)

14 Pantalone KM \& Nasr C. Approach to a low TSH level: patience is a virtue. Cleveland Clinic Journal of Medicine 201077 803-811. (https:// doi.org/10.3949/ccjm.77a.10056)

15 Gaitonde DY, Rowley KD \& Sweeney LB. Hypothyroidism: an update. American Family Physician 201286 244-251.

16 De Leo S, Lee SY \& Braverman LE. Hyperthyroidism. Lancet 2016388 906-918. (https://doi.org/10.1016/S0140-6736(16)00278-6.)

17 Iglesias P, Ridruejo E, Muñoz A, Prado F, Macías MC, Guerrero MT, Tajada P, García-Arévalo C \& Díez JJ. Thyroid function tests and mortality in aged hospitalized patients: a 7-year prospective observational study. Journal of Clinical Endocrinology and Metabolism 201398 4683-4690. (https://doi.org/10.1210/jc.2012-3849.)

18 Helfand M \& Crapo LM. Screening for thyroid disease. Annals of Internal Medicine 1990112 840-849. (https://doi.org/10.7326/00034819-112-11-840)

19 Attia J, Margetts P \& Guyatt G. Diagnosis of thyroid disease in hospitalized patients: a systematic review. Archives of Internal Medicine 1999159 658-665. (https://doi.org/10.1001/archinte.159.7.658)

20 Spencer CA, LoPresti JS, Patel A, Guttler RB, Eigen A, Shen D, Gray D, Nicoloff JT. Applications of a new chemiluminometric thyrotropin assay to subnormal measurement. Journal of Clinical Endocrinology and Metabolism 199070 453-460. (https://doi.org/10.1210/jcem-70-2453)

21 Adler SM \& Wartofsky L. The nonthyroidal illness syndrome. Endocrinology Metabolism Clinics of North America 200736 657-672, vi. (https://doi.org/10.1016/j.ecl.2007.04.007)

Received in final form 17 March 2018

Accepted 23 March 2018

Accepted Preprint published online 23 March 2018 http://www.endocrineconnections.org https://doi.org/10.1530/EC-18-0004
(อ2018 The authors Published by Bioscientifica Ltd

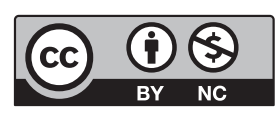

This work is licensed under a Creative Commons Attribution-NonCommercial 4.0 International License. 